Research Reports

\title{
Nucleus basalis prosencephali, a substrate of apomorphine-induced pecking in pigeons
}

\author{
Ulrike Lindenblatt and Juan D. Delius* \\ Experimentelle Tierpsychologie, Psychologisches Institut, Ruhr-Universität Bochum, Bochum (F.R.G.)
}

Key words: Apomorphine; 6-Hydroxydopamine; Stereotyped pecking; Nucleus basalis; Pigeon

\begin{abstract}
Microinjections of the dopamine agonist apomorphine into the nucleus basalis prosencephali of pigeons elicit stereotyped pecking behaviour. Injections of 6-hydroxydopamine, a toxic dopamine antagonist, into the same nucleus impair stereotyped pecking induced by systemic apomorphine administration, but do not interfere with pecking in the normal feeding context.
\end{abstract}

\section{INTRODUCTION}

The drug apomorphine is well known to be a potent agonist of the transmitter, dopamine ${ }^{22}$. When given systemically to animals it frequently elicits, among some other stereotypes, oral behaviours, which resemble feeding responses. Apomorphine-induced feeding behaviour components such as grazing, snapping, pecking, biting, gnawing and chewing have been observed in animals as diverse as snails ${ }^{37}$, amphibians (J.P. Ewert, personal communication) reptiles $^{3}$, birds $^{2,30}$ and mammals ${ }^{19,20,25}$.

Pigeons will begin to peck within a few minutes after an intramuscular (i.m.) injection of an optimally effective dose of about $1 \mathrm{mg} / \mathrm{kg}$ apomorphine, continue for nearly $90 \mathrm{~min}$, reaching a maximum rate of about $150 \mathrm{pecks} / \mathrm{min}$ some $10 \mathrm{~min}$ after injection, pecking altogether some 5000 times. In comparable circumstances, saline-injected control-pigeons on average peck less than once ${ }^{11}$. If small contrasting visual stimuli are offered in the testing environment, the pecks tend to be directed at these; the targets also augment the frequency of pecking ${ }^{4,8}$. Pigeons will, however, also exhibit apomorphine-induced pecking in absolute darkness (own observations).

Though the apomorphine-pecking is superficially reasonably similar to that shown during feeding, there is evidence that it is not equivalent to food pecking or conditioned pecking. Even though the birds will peck grain under apomorphine they do not normally swallow $\mathrm{it}^{28}$. Apomorphine actually has an anorexic effect ${ }^{16}$. Food-reinforced operant pecking is only facilitated by apomorphine when pigeons accidentally aim their stereotyped pecking at the operandum; otherwise the apomorphine pecking interferes with instrumental responding and decreases response rates ${ }^{1,24}$.

Not much is known about the neural site or sites at which apomorphine acts to elicit feeding-related behaviour among vertebrates ${ }^{21,23}$. Birds may be convenient subjects in which to pursue this question because a number of recent anatomical, physiological and behavioural studies have led to the identification of the neural network involved in the control of feeding behaviour ${ }^{11,18,35,36,41}$.

A $\left[{ }^{14} \mathrm{C}\right]$ deoxyglucose autoradiography study ${ }^{13}$ (see also ref. 11) revealed that apomorphine-induced pecking fits in pigeons are accompanied by an in-

* Present address: Fachgruppe Psychologie, Universität Konstanz, D-7750 Konstanz, F.R.G.

Correspondence: U. Lindenblatt, Experimentelle Tierpsychologie, Psychologisches Institut, Ruhr-Universität Bochum, D-4630 Bochum, F.R.G. 
creased glucose uptake in a considerable number of brain structures, among them the nucleus basalis area. This accords with histochemical evidence that this area contains dopamine ${ }^{32}$. The autoradiographic method, however, leaves open whether the activation of a given structure is primarily induced by apomorphine or due to secondary effects. Activation might, for example, be due to reafferent sensory stimulation arising from the pecking behaviour induced by apomorphine. This is an issue in the case of the nucleus basalis because it is the terminal of several sensory pathways that are inevitably activated during pecking (it receives olfactory, somesthetic, auditory and vestibular input $)^{34-36}$. Also, it remains uncertain whether a structure revealed by autoradiography necessarily is involved in the control of pecking since dopaminoceptive structures involved in the control of other behaviour than pecking could be simultaneously though subliminally activated.

This problem could be resolved by local application of apomorphine. A preliminary series of intracerebral microinjections in pigeons (Audick and Delius, unpublished observation) using racemic apomorphine suggested that the nucleus basalis but not other, neighbouring fronto-telencephalic structures could be activated to yield pecking. The first experiment sought to confirm that the stereotyped pecking elicited by apomorphine involves a structure that the studies mentioned above identify as playing a central role in the control of feeding in birds: the nucleus basalis prosencephali. Advantage was taken of the availability of two enantiomers of apomorphine, one levorotating (L) pharmacologically fully active, and the other dextrorotating (D) and inactive.

In the second experiment, 6-hydroxydopamine (6OHDA), a toxic agent for catecholaminergic structures, was employed. It is taken up by terminals and dendrites of catecholamine-containing neurons and destroys these cells. This experiment examined whether 6-OHDA lesions of nucleus basalis would have any effect on pecking induced by systemic administration of apomorphine.

\section{MATERIALS AND METHODS}

Fourteen adult homing pigeons of local stock were used for the first experiment. They were individually housed in cages in a well ventilated and brightly illu- minated ( $12 \mathrm{~h}$ on, $12 \mathrm{~h}$ off) animal room.

The pigeons were habituated to a test cage ( $45 \times$ $40 \times 35 \mathrm{~cm}$ ) during 4 daily sessions lasting $45 \mathrm{~min}$. Three side walls and the ceiling of this cage were lined with black cardboard peppered with yellow circular dots $\left(8 \mathrm{~mm}\right.$ diameter, 10 per $\left.\mathrm{dm}^{2}\right)$. Immediately before the two last habituation sessions they were injected with $1 \mathrm{mg} / \mathrm{kg} \mathrm{b}$. wt. racemic apomorphine in $0.5 \mathrm{ml}$ saline to induce a sensitization to the drug (the behavioural response to a constant apomorphine dose initially increases with successive injections) $)^{10.11}$. All subjects exhibited pecking fits as described above.

Each pigeon was stereotaxically implanted with up to 4 chronic intracerebral guide cannulas while under general anaesthesia ${ }^{31}$. Maximally 2 of the cannulas were aimed at the anterior telencephalon, the area of interest for this report. The cannulas were made of pieces of stainless steel hypodermic tubing $(9 \mathrm{~mm}$ length, $0.7 \mathrm{~mm}$ o.d.). They were introduced vertically $4 \mathrm{~mm}$ deep into the brain through trephines in the skull at predetermined anterior/lateral stereotaxic coordinates and cemented into place with dental acrylic. A stainless steel needle plug $(0.3 \mathrm{~mm}$ diameter) equipped with an elastic polythene collar sealed the cannulas while they were not in use.

The animals were left to recover for at least 3 days before intracerebral microinjection trials began. For the apomorphine application an injection cannula of predetermined length (selected to reach the target structure) an $0.3 \mathrm{~mm}$ o.d. was introduced through the lumen of the guide cannula and into the brain tissue. The injection cannula was connected with a short length of plastic tubing to a $10 \mu \mathrm{l}$ syringe that was preloaded with destilled water and with $1 \mu \mathrm{l}$ of either Lor D-apomorphine solution ( $20 \mu \mathrm{g}$ in $1 \mu \mathrm{l}$ deoxygenated water with $0.01 \mu \mathrm{g}$ sodium disulfite as antioxidant).

The first injection into a given brain location was always of the dopamine agonist L-apomorphine. Immediately after the microinjection the pigeon was placed into the test cage and observed through a oneway screen from an adjacent room. An electronic timer produced faint blips every $30 \mathrm{~s}$. A prepared check-grid, listing the 16 most common behaviours exhibited by pigeons in this particular situation was used to record the responses observed during successive $30 \mathrm{~s}$ periods. Observations lasted for $20 \mathrm{~min}$ un- 
less the subject showed an unusually protracted behavioural response in which case the observation was extended to $40 \mathrm{~min}$. If the initial L-apomorphine injection yielded pecking, a week later the same site was injected with the inactive $\mathrm{D}$-apomorphine as a control and a further week later again with L-apomorphine.

After completion of the observation series and $24 \mathrm{~h}$ before sacrifice, the injection sites were marked with an infusion of $1 \mu \mathrm{l}$ of a $5 \%$ ferric chloride solution. For perfusion the animals were anaesthetized and transcardially flushed first with Ringer $(0.9 \%$ sodium chloride solution) and then with formalin (4\% formaldehyde plus $1 \%$ potassium hexacyanoferrate solution). The head was conserved in formalin solution. Later the brain was extracted, embedded in eggyolk, hardened with formalin vapours and cut transversally at $40 \mu \mathrm{m}$ with a freezing microtome. The injection sites could be easily detected during sectioning due to a Prussian blue reaction stain. Relevant sections were stained with Cresyl violet and coverslipped. The injection sites were identified with the aid of a microscope and transferred to standard brain atlas drawings ${ }^{27}$.

In the second experiment 11 drug-naive pigeons kept as before were used. The test cage was the same as in the preceding experiment. The subjects were habituated and sensitized in the same way as in the previous experiment except that the second sensitization session was employed to establish a behavioural baseline. Only $0.5 \mathrm{mg} / \mathrm{kg}$ apomorphine were injected i.m. and the pecking of the pigeon was recorded in the test cage. The subjects were then implanted with 4 guide cannulas using the same technique as described before. A special effort was made to place the anterior pair symmetrically over the left and the right nucleus basalis. The posterior pair of cannulas are not relevant in the present context.

Microinjections were carried out with the same technique as described before. Each injection involved $1 \mu \mathrm{l}$ of a solution containing $2 \mu \mathrm{g} 6-\mathrm{OHDA}$ and $0.2 \mu \mathrm{g}$ ascorbic acid (as antioxidant). First one brain side was injected. Four hours and $24 \mathrm{~h}$ later the bird was observed in the test cage after i.m. administration of $0.5 \mathrm{mg} / \mathrm{kg}$ apomorphine. Forty-eight hours later the other brain side was injected with 6-OHDA. One bird incidentally received closely neighbouring double injections on each brain side. The birds were observed again in the test cage after further apomorphine administration 4,24 and $48 \mathrm{~h}$ later.

In 5 of the 12 animals we also examined the effect of the 6-OHDA upon unconditioned food pecking and upon instrumentally conditioned pecking. The pigeons were maintained at $80 \%$ of their normal weight by controlled feeding. For the assessment of unconditioned pecking we employed a task involving the selection of 30 safflower grains from among $30 \mathrm{~g}$ of quartz gravel, a difficult discrimination task for humans (cf. ref. 6). The grain/gravel mixture was offered in a transparent trough measuring $9 \times 5 \times 6.5$ $\mathrm{cm}$ that replaced the metal trough of the same dimensions normally attached to the pigeon's home cage. The measures assessed were the number of pecks emitted during a $30 \mathrm{~s}$ period beginning with the first peck into the trough and the number of safflower grains consumed during the same period. Baseline tests took place 72,48 and $24 \mathrm{~h}$ before the first 6 OHDA injections. The tests were repeated 3 and 23 $\mathrm{h}$ after that injection and again 3,23 and $47 \mathrm{~h}$ after the second injection of 6-OHDA.

For instrumental conditioning pecking tests the pigeons were pretrained to peck a green light-emitting diode mounted on a piezoceramic element glued onto a heavy metal ledge that replaced the normal food trough of the pigeon's home cage. Pecks on the illuminated diode activated, through programming equipment, an electromagnetic grain dispenser that dropped a few grains of millet into a small circular trough located next to the peck transducer on the metal ledge. Initially the animals received a reward for each peck but in later sessions they were rewarded only for on average, every 5 th peck (variable ratio 5 schedule of reinforcement). Pecks on the diode were counted automatically. Sessions lasted 10 min and were repeated daily; between 17 and 20 sessions were necessary until the pigeons pecked steadily. Three sessions 71,47 and $23 \mathrm{~h}$ before the first 6OHDA injection served as baseline. Further test sessions took place 3.5 and $23.5 \mathrm{~h}$ after the first, and 3.5 , 23.5 and $47.5 \mathrm{~h}$ after the second 6-OHDA microinjection.

Three to 8 weeks after the end of the above observation series (during this period tests took place that involved the posterior cannulas) the subjects were perfused as before except that no iron/Prussian blue marking was performed. The histological processing 
was otherwise as described before.

\section{RESULTS}

In the first experiment 22 apomorphine injection sites were located in the anterior telencephalon (between stereotaxic planes A 13 and A 11, see ref. 27; results referring to injections in more posterior areas will be reported elsewhere). Eight of the sites yielded pecking activity upon injections with $\mathrm{L}$-apomorphine. Pecking always began within the first $4 \mathrm{~min}$ after injection and continued for between 5 and $20 \mathrm{~min}$, in one case for $40 \mathrm{~min}$, reaching a maximum rate of between 20 and $50 \mathrm{pecks} / \mathrm{min}$. None of these sites
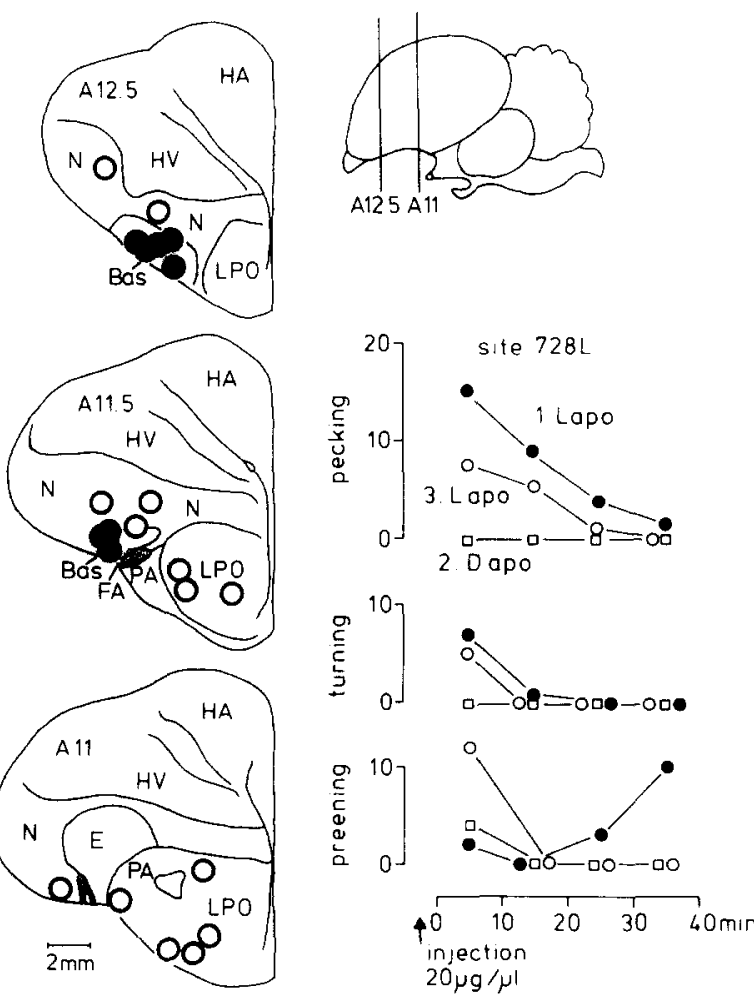

Fig. 1. Location of the apomorphine injection sites in the frontal forebrain of the pigeon. Full circles, sites yielding pecking; empty circles, sites not yielding pecking. Abbreviations: Bas, nucleus basalis; E, ectostriatum; FA, tractus frontoarchistriatalis; HA, hyperstriatum accessorium; HV, hyperstriatum ventrale; LPO, lobus parolfactorius; N, neostriatum; PA, paleostriatum augmentatum. Pecking, turning and preening induced by microinjection of apomorphine into the nucleus basalis of the pigeon, an example of the time course. Abscissae represent the number of $30 \mathrm{~s}$ periods per $10 \mathrm{~min}$ in which the corresponding behaviour was shown. yielded pecking on injection with D-apomorphine but 6 produced a further albeit weaker pecking fit upon the second L-apomorphine injection (Fig. 1).

Of the 8 sites 7 also yielded contralateral turning with L-apomorphine but not with D-apomorphine. In most instances turning behaviour was displayed dur-
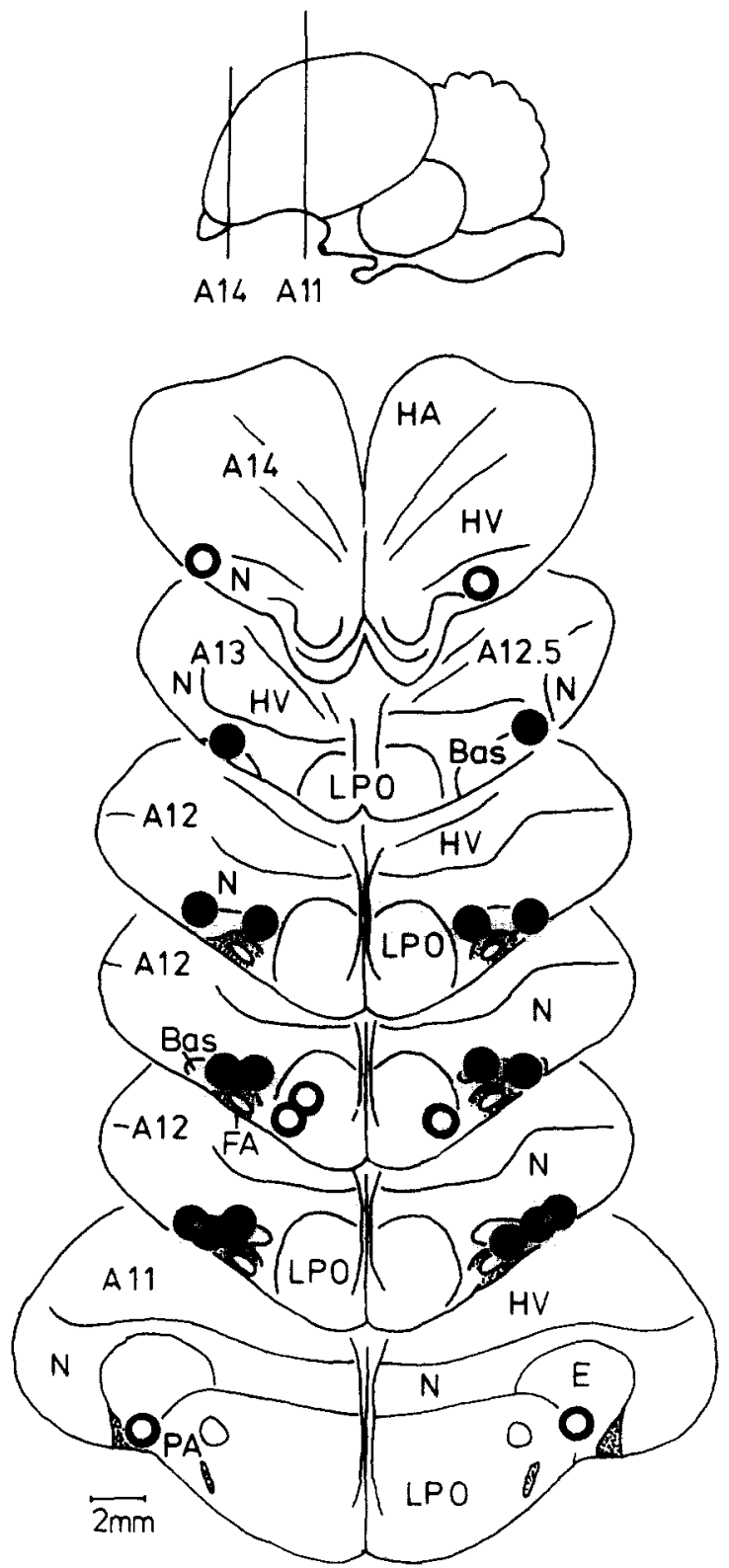

Fig. 2. Location of the 6-OHDA lesions in the frontal forebrain of the pigeon. Full circles, lesions in the nucleus basalis; open circles, control lesions in neighbouring structures. Double lesions are marked linked with a white bar. Abbreviations as in Fig. 1. 
ing the pecking bouts: the pigeons successively aimed at locations on the contralateral side with respect to the injection site. Maximally they produced about 20 full turns in $20 \mathrm{~min}$. Seven of the 8 sites yielded some preening. These were fragmentary, short episodes compared to the normal preening behaviour. The remaining 14 sites did not yield pecking. None of these produced turning but preening was induced in 5 sites. Swallowing and head shaking was apparent in 18 of 22 sites. When classified according to locations all 8 sites yielding pecking were found to be within or on the border of the nucleus basalis prosencephali (Fig. 2). Only one site situated in this nucleus did not yield pecking (it produced preening). The other 13 sites not yielding pecking were all located in neighbouring forebrain structures (neostriatum, lobus paraolfactorius), the sites yielding swallowing did not cluster in any particular structure and furthermore these responses were also frequently elicited by $\mathrm{D}$-apomorphine control injections.

The lesions caused by the 6-OHDA injections as far as they could be detected microscopically were small, less than $1 \mathrm{~mm}$ in diameter, and somewhat ir- regular in shape (Fig. 2). In 7 of the 11 pigeons the locations of the bilateral 6-OHDA injection sites, as identified by these lesions, were within or encroaching on the nucleus basalis. In 4 pigeons the injection sites were located in neighbouring frontal forebrain structures (neostriatum, lobus parolfactorius, ectostriatum): they served as controls (Fig. 2; results relating to injections in structures posterior to the stereotactic plane A 11 as before are not dealt with here).

Following the 6-OHDA injections into the basalis there was a marked decline in apomorphine pecking, whereas there was little or no decline in 4 subjects that had injections in control sites (Fig. 3). An analysis of variance showed the post-treatment effects to be significant $\left(F_{1,9}=31.54, P<0.01\right)$.

The 5 birds that were tested for grain pecking and conditioned pecking had all their 6-OHDA injections placed into the nucleus basalis. As Fig. 3 shows they did evince only a slight (non-significant) decay in conditioned pecking and no deficit in grain/gravel pecking after the lesioning. The number of safflower grains consumed (not shown), an index of grain/gra-

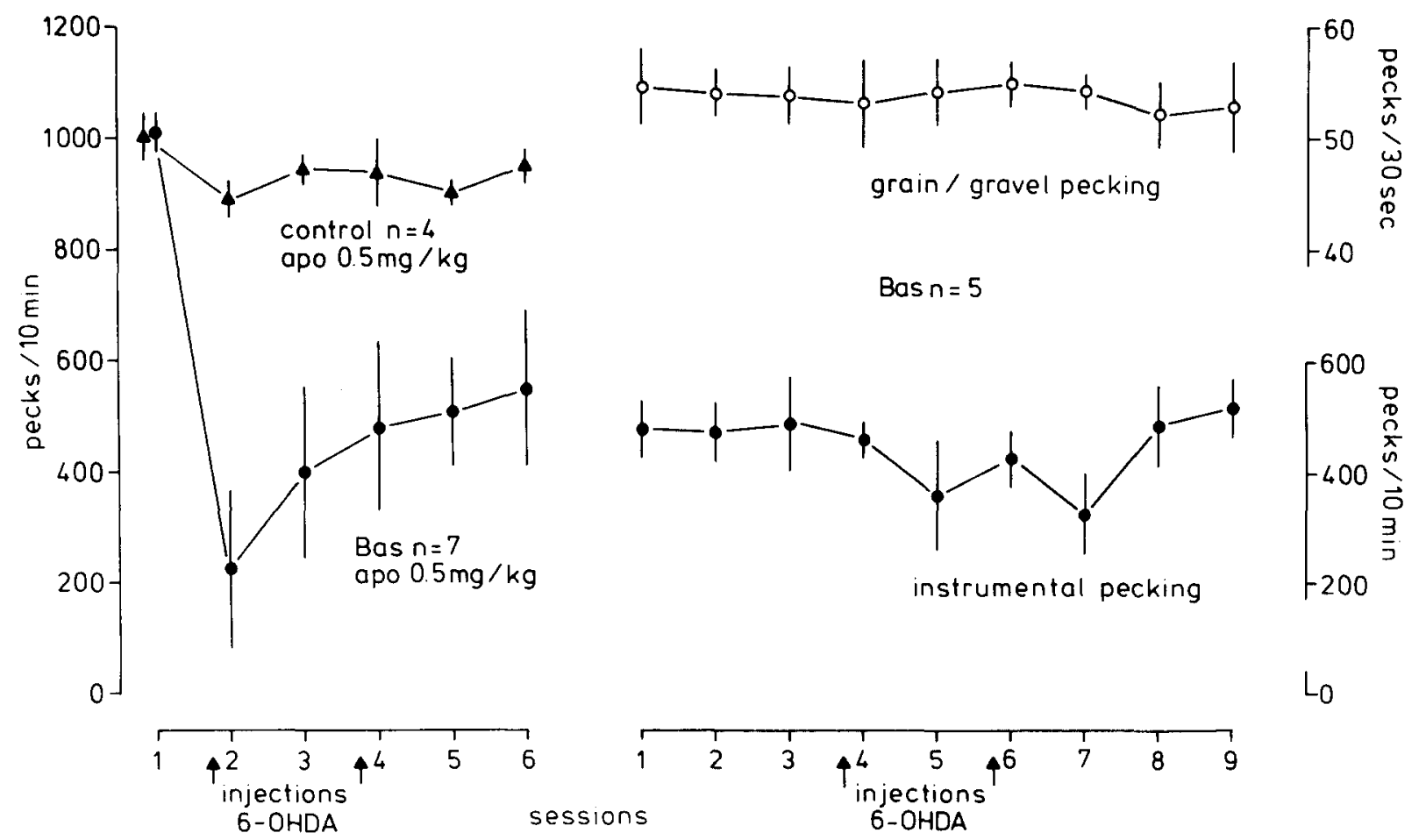

Fig. 3. The effect of 6-OHDA lesions of nucleus basalis and control structures upon pecking induced by i.m. apomorphine (left) and upon food pecking and conditioned pecking (right). 
vel discrimination, was similarly unaffected by the lesions.

\section{DISCUSSION}

The results of the apomorphine injections confirm and extend the findings of the preliminary studies. The present data shows that the pecking is elicited specifically by the activation of dopaminoceptive structures in the nucleus basalis area and is not an unspecific injection response since $D$-apomorphine had no effect.

6-OHDA injections into the nucleus basalis markedly suppressed apomorphine-induced pecking. The implication is that apomorphine acts there mainly via dopamine autoreceptors. It is not known though whether the dopamine normally impinging on these autoreceptors stems from local or from remote neurons, as autoreceptors may be located on perikarya/dendrites or on axonal terminals.

In any case the nucleus basalis area is at least part of the neural structures on which systemically applied apomorphine acts to activate pecking. Remarkably, however, normal grain pecking and pecking conditioned with food reward was not affected by the 6OHDA lesions. This is in agreement with the evidence that apomorphine pecking, though superficially similar to the initial phases of normal food pecking does not normally lead to food consumption ${ }^{9.28}$. Also, lesions of the nucleus basalis brought about by other means than by 6-OHDA in our experience do not markedly affect the gross execution of food or conditioned-pecking. They may, however, affect finer details of such pecking.

In general the results of the two experiments reported here support the hypothesis that systemically administered apomorphine acts upon the nucleus basalis prosencephali to elicit the characteristic stereotyped pecking. That the effect of the basalis injections might have been due to apomorphine diffusing to other structures, the paleostriatum for example (see below), is unlikely because of the failure to obtain pecking with injections in control structures bordering with the basalis and the paleostriatum. Injections of higher doses $(60 \mu \mathrm{g})$ of apomorphine into the forebrain ventricles, another potential leakage route, did not elicit pecking ${ }^{15}$.

It would be erroneous though to conclude that the basalis is the only structure on which apomorphine acts to have that effect. An earlier report ${ }^{23}$ indicates that i.c. injections of apomorphine into the paleostriatum also can evoke pecking. Our preliminary findings support that ${ }^{28}$. The paleostriatum is the terminal of a major dopaminergic pathway originating in the mesencephalic nucleus tegmenti pedunculopontinus pars compacta, the homologue of the mammalian substantia nigra in birds ${ }^{7}$. At present it is not certain, however, how the paleostriatum influences the feeding behaviour. Schall et al. mention paleostriatal neurons that project upon the nucleus basalis. It is interesting though that the paleostriatal complex of birds is thought to be homologous to the basal ganglia of mammals. These structures have been implicated as substrates of apomorphine-induced stereotypes in these animals ${ }^{21,33}$. The connection with the nucleus basalis is more apparent for another structure, the archistriatum for which preliminary results also suggest that apomorphine microinjections elicit pecking. A massive pathway, the tractus frontoarchistriatalis originating in the neostriatum frontale, which is closely interconnected with the nucleus basalis, terminates in the anterior archistriatum dorsale $36,38,39$

Apomorphine microinjections into the nucleus basalis also induced turning and preening. Turning appears to be a consequence of a unilateral activation of pecking/preening. As the animals attempt to peck preen with an aim lateral to their midline they begin to circle. The fact that preening is elicited by apomorphine stimulation of the basalis suggests that this structure is also involved in the control of that behaviour (more evidence to that effect in refs. 28; see also ref. 12). Low doses of systemic apomorphine that do not quite induce pecking fits may facilitate preening ${ }^{17}$. As preening involves movements not unlike pecking, that might not be so unexpected.

It could be that a coactivation of feeding-related pecking and preening-related pecking is the reason for the peculiarities of apomorphine-induced pecking mentioned earlier. These have in the past led to controversy as to whether it is homologous to pecking during feeding (compare, for example, refs. 8 and 9). Alternatively, it may be that apomorphine is only capable of stimulating part of the pecking control system normally active during feeding; or that dopaminergic mechanisms are simultaneously involved both 
in the control of pecking and of satiety (anorexic effect of apomorphine mentioned earlier) ${ }^{16}$. The results of the second experiment underline the fact that apomorphine pecking is not homologous to feeding pecking. 6-OHDA-lesions of the nucleus basalis did not affect pecking in a feeding context nor conditioned pecking reinforced by food, although they significantly suppressed apomorphine-induced pecking. We are reluctant though to conclude that the nucleus basalis is not at all concerned with the control of operant and feeding pecking. There is too much other evidence that it is involved ${ }^{11,34,35}$. Recent experiments (Schall, in preparation) show that basalis lesions do indeed lead to subtle deficits in discriminative instrumental pecking.

There is evidence that in mammals dopaminergic pathways/mechanisms are part of the reward signalling systems that are tapped in intracranial self-stimulation experiments ${ }^{40}$. Rats indeed learn to work for intravenous apomorphine injections ${ }^{5}$. In accordance

\section{REFERENCES}

1 Abelson, J.S. and Woods, J.H., Effects of apomorphine on elicited and operant pecking in pigeons, Psychopharmacology, 71 (1980) 237-241.

2 Amsler, C., Beiträge zur Pharmakologie des Gehirns, Arch. Exp. Pathol. Pharmakol., 97 (1923) 1-27.

3 Andersen, H., Braestrup, C. and Randrup, A., Apomorphine induced biting in the tortoise in relation to dopaminergic mechanisms, Brain Behav. Evol., 11 (1975) 365-372.

4 Basten-Kreft, A., Apomorphin-induziertes Verhalten bei Tauben, Diploma thesis, Bochum, 1977.

5 Baxter, B.L., Gluckman, M.I., Stein, L. and Scerni, R.A., Self-injection of apomorphine in the rat: positive reinforcement by a dopamine receptor stimulant, Pharmacol. Biochem. Behav., 2 (1974) 387-392.

6 Bond, A.B., Visual search and selection of stimuli in the pigeon: the attention threshold hypothesis, J. Exp. Psychol. Anim. Behav. Proc., 9 (1983) 292-306.

7 Brauth, S.E., Ferguson, J.L. and Kitt, C.A., Prosencephalic pathways related to the paleostriatum of the pigeon ( $\mathrm{Col}$ umba livia), Brain Research, 147 (1978) 205-221.

8 Brunelli, M., Magni, F., Moruzzi, G. and Musumeci, D., Apomorphine pecking in the pigeon, Arch. Ital. Biol., 113 (1975) 303-325.

9 Cheng, H.C. and Long, J.P., Dopaminergic nature of apomorphine-induced pecking in pigeons, Eur. J. Pharmacol., 26 (1974) 313-320.

10 Costentin, I., Protais, P. and Schwartz, J.C., Rapid and dissociated changes in sensitivities of different dopamine receptors in mouse brain, Nature (Lond.), 257 (1975) 405-407.

11 Delius, J.D., The peck of the pigeon: free for all. In C.F. Lowe, M. Richelle, D.E. Blackman and C.M. Bradshaw (Eds.), Behaviour Analysis and Contemporary Psychology, with that systemically administered apomorphine is an effective reinforcer for an excitatory classical conditioning of pecking in pigeons ${ }^{29}$. Current experiments indicate that such injections also function as a reinforcer in an instrumental conditioning of place preferences in these birds. It seems possible that the nucleus basalis is involved in this effect as it also supports electrical brain self-stimulation in pigeons ${ }^{14,42}$. Future work will address this hypothesis.

\section{ACKNOWLEDGEMENTS}

This research was supported by a grant of the Graduiertenförderung (NRW) to U.L. and by the Deutsche Forschungsgemeinschaft through its Sonderforschungsbereich 114 . We thank D. Hagenkötter for preparing the manuscript. U. Schall and Drs. O. Güntürkün and S.E.G. Lea read a draft and made many useful suggestions.

Erlbaum, New York, 1985, pp. 53-81.

12 Delius, J.D., Preening and related comfort behaviour in birds, Ann. N.Y. Acad. Sci., in press.

13 Delius, J.D. and Scheich, H., Deoxyglucose incorporation by the pigeon brain during apomorphine and instrumental pecking, in preparation.

14 Delius J.D. and Pellander, K., Hunger dependance of electrical brain self-stimulation in the pigeon, Physiol. Behav., 28 (1982) 63-66.

15 Deviche, P., Stereotyped behaviour affected by peripheral and intracerebroventricular apomorphine administration in pigeons, Pharmacol. Biochem. Behav., 18 (1983) 323-326.

16 Deviche, P., Administration of small doses of apomorphine attenuates feeding in non-deprived pigeons, Physiol. Behav., 33 (1984) 581-585.

17 Deviche, P., Behavioral response to apomorphine and its interaction with opiates in domestic pigeons, Pharmacol. Biochem. Behav., 22 (1985) 209-214.

18 Dubbeldam, I.L., Brauch, C.S.M. and Don, A., Studies in the somatotopy of the trigeminal system in the mallard, Anas platyrhynchos L. III. Afferents and organization of the nucleus basalis, J. Comp. Neurol., 196 (1981) 391-405.

19 Ernst, A.M. and Smelik, P.G., Site of action of dopamine and apomorphine on compulsive gnawing behavior in rats, Experientia, 22 (1966) 837-838.

20 Fekete, M., Kurti, A.M. and Pribusz, J., On the dopaminergic nature of the gnawing compulsion induced by apomorphine in mice, J. Pharm. Pharmacol., 22 (1970) 377-379.

21 Fog, R., Randrup, A. and Pakkenberg, H., Lesions in corpus striatum and cortex of rat brains and the effects on pharmacologically induced stereotyped, aggressive and cataleptic behaviour, Psychopharmacology, 18 (1970) 346-356.

22 Goodman Gilman, A., Goodman, L.S. and Gilman, A. (Eds.), The Pharmacological Basis of Therapeutics, Mac- 
millan, New York, 1980

23 Goodman, I.J. and Stitzel, R.E., Corpus striatal (paleostriatal complex) interventions and stereotyped behaviours in pigeons, Soc. Neurosci. Abstr., (1977).

24 Graeff, F.G. and de Oliveira, L., Influence of response topography on the effect of apomorphine and amphetamine on operant behavior of pigeons, Psychopharmacology, 41 (1975) 127-132.

25 Harnack, E., Über die Wirkung des Apomorphins am Säugethier und am Frosch. Arch. Exp. Pathol. Pharmakol., 2 (1874) 254-306.

26 Jonsson, G., Lesion methods in neurobiology, In $\mathrm{Ch}$. Heym, and W.-G., Forssman, (Eds.), Techniques in Neuroanatomical Research, Springer, Berlin, 1981.

27 Karten, H.J. and Hodos. W., A Stereotaxic Atlas of the Brain of the Pigeon, Johns Hopkins Press, Baltimore, MD, 1967.

28 Lindenblatt, U., Die dopaminerge Auslösung des Pickverhaltens bei Tauben, Ph.D. Thesis, Bochum, 1986.

29 Lindenblatt, U. and Delius, J.D., Apomorphine-induced pecking in pigeons classically conditioned to environmental cues, Psychopharmacology, 93 (1987) 223-225.

30 Machlis, L., Apomorphine: effects on timing and sequencing of pecking behaviour in chicks, Pharmacol. Biochem. Behav., 13 (1980) 331-336.

31 Mallin, $H$. and Delius, J.D., Inter- and intraocular transfer of colour discriminations with mandibulation as an operant in the head-fixed pigeon, Behav. Anal. Lett., 3 (1983) 297-309.

32 Minelli, G., Ricerche istochimiche dell' encephalo di Testu- do graeca e Coturnix coturnix, Riv. Biol., 63(1970) 61-8h

33 Reiner, A., Brauth, S.E. and Karten, H.J., Evolution of amniote basal ganglia, Trends Neurosci. 7 (1984) 320-325.

34 Schall, U., Vestibular, olfactory, and vibratory responses of nucleus basalis prosencephali neurons in pigeons, Neurosci. Res., 4 (1987) 376-384.

35 Schall, U. and Delius. J.D.. Sensory inputs to the nucleus basalis prosencephali, a feeding-pecking center in the pigeon, J. Comp. Physiol., 159 (1986) 33-41

36 Schall, U., Güntürkün, O. and Delius, J.D., Sensory projections to the nucleus basalis prosencephali of the pigeon. Cell Tiss. Res., 245 (1986) 539-546.

37 Wieland, S.J. and Gelperin, A., Dopamine elicits feeding motor program in Limax maximus. J. Neurosci. 3 (1983) $1735-1745$

38 Wild, J.M., Arends, J.J.A. and Zeigler, H.P., A trigeminal sensorimotor circuit for pecking, grasping and feeding in the pigeon (Columba livia), Brain Research, 300 (1984) $146-151$

39 Wild. J.M. . Arends, J.J.A. and Zeigler, H.P., Telencephalic connections of the trigeminal system in the pigeon ( $\mathrm{Col}$ umba livia): a trigeminal sensorimotor circuit, J. Comp. Neurol., 234 (1985) 441-464.

40 Wise, R.A., Catecholamine theories of reward: a critical review, Brain Research, 152 (1978) 215-247.

41 Zeigler, H.P., Feeding behavior of the pigeon. Adv. Study Behav., 7 (1976) 285-389.

42 Zeigler, H.P., Hollard, V.D., Wild, J.M. and Webster, D.M., Intracranial self-stimulation from endbrain nuclei in the pigeon, Physiol. Behav., 21 (1978) 387-394 